\section{SOUTH-WEST LONDON MEDICAL SOCIETY.}

JoHN GAY, L.R.C.P., M.R.C.S., President, in the Chair. Wednesday, November 13th, 1901.

'The $X$ Rays in Cancer.

Mr. Cercil R. C. Lyster, Medical Superintendent of Bolingbroke Hospital, Wandsworth Common, brought before the Society two cases of local cancerous disease treated by the $x$ rays at the Bolingbroke Hospital. His experience of $x$-ray work dated from June, 1900, when, by the kindness of one of the Board, Mr. Mackrell, he was enabled to purchase a Wimshurst induction machine and vacuum tube apparatus, very largely for the purpose of treating a case of lupus in which they were interested. Success resulted, and other successes followed. He next treated a rodent ulcer of the outer canthus of the right eye, and was as fortunate as hitherto. Studying with some care the pathological effect of this new-found remedy, he eventually formed the opinion that the diseased tissues were gradually thrown off in the form of crusts and scabs, or absorbed. This belief induced him to apply the Roentgen rays on the first of the two patients whom he showed. J. L., aged 65 , a knife-grinder and tinker by trade, came to Mr. Lyster on March Ist, I9OI, complaining of a sore on the lower lip. On examination, he found the lower lip everted, there was a hard growth, an inch by three-quarters of an inch, slightly to the left side of the middle line, and a foul ulcer, the size of a sixpence, at the junction of the skin with the mucous membrane, extending from the middle line towards the left. The edges were indurated, irregular, and markedly everted. It was, in short, a typical epithelioma. For the reason stated above, Mr. Lyster treated this in the same way as his lupus cases had hitherto been treated, and with the usual ro-inch tube. The rays were applied on March 5 th, 6 th, 7th, 8th, 9th, and I th, giving sittings of ten minutes, with resulting congestion. The ulcer was now discharging a thin, serous fluid, and a healthy granulating surface was beginning to make an appearance. Treatment was discontinued until March 19th, by which time the congestion was disappearing, the ulcer being smaller, cleaner, and definitely not so hard as before. He again applied the $x$ rays on March igth, 2oth, 2ist and 22nd. Less congestion resulted, and the ulcer daily grew smaller and healthier. Treatment as hitherto was continued on March 25th and 26th and on the first three days of April ; marked diminution in the size of the ulcer and growth being manifest. The rays were applied for the last time on April roth, 1901, by which time the ulcer had practically healed, and except for a slight scar the lip looked normal, although some slight thickening towards the middle line was still apparent. He told the patient to come again as usual, but considering the cure to be complete, the order was not obeyed, and they had not seen him until this evening, having been at some pains to discover his whereabouts to bring him before the Society. Mr. Lyster added that the patient was somewhat addicted to $\mathrm{C}_{2} \mathrm{H}_{6} \mathrm{O}$, and was for various other reasons-obvious to all bystanders-not the person one would have chosen in order to demonstrate rapid healing under a new treatment. The treatment of all their $x$-ray cases had been carried out by $\mathrm{Mr}$. Lyster and by his assistant, $\mathrm{Mr}$. Eric M. Perkins, and it was intimated that they would be glad to demonstrate their methods and appliances to any member of the Society.

$\mathrm{Mr}$. Lyster then read a communication to the Society from Mr. Thomas Bryant, F.R.C.S., to the following effect:As I well know how interested every member of your Society is in the work carried on at the Bolingbroke Hospital, I wish to report the result of our experience in the treatment of cutaneous and subcutaneous cancer by the $x$ rays. You probably are all aware of the striking beneficial influence of these rays in the treatment of lupus, for the examples of its successful application have been numerous and must be known to all of you. But you may not be acquainted with the fact that we have had at Bolingbroke good success in the treatment. of rodent and epithelial skin ulcers, and in one typical example of epithelial tumour of the lower lip of an old man, which did not seem suitable for a surgical operation which Mr. Lyster treated and will show to-night. Indeed it has been from these successes that Mr. Lyster and myself have been induced to try the treatment upon a case of recurrent cancer of the breast which came under my care in private work, and its influence has been so remarkably beneficial, and the lady patient is quite ready to submit herself to your inspection. I have taken the occasion of this meeting of your Society to send you this report of our doings. The patient you will see is about forty-three years of age, and came into my hands in August, rgor, for a recurrent cancerous disease involving the seat of an operation which I had performed in December, 1900, and which had manifested itself about one month before I saw her, and seven months after the original operation. The clavicular flap was the seat of tubercles of a florid red colour, and the lower flap near the original scar was dotted with like tubercles. The upper flap near its axillary end was also the seat of a raised tumour, the size of a crown, the surface of which was breaking down. In front of this tumour was a second, situated beneath the skin, with a convex surface, and apparently infiltrating its deeper layers, as the skin over it was fixed. There was likewise a tubercle in the scar at its extreme axillary end. A rough diagrammatic drawing of the case, as it appeared when the treatment was first commenced, will be laid before you. I may add that the patient complained of much pain at the seat of disease. At the present time-three months after continuous treatment-it has to be reported that in this case all pain has ceased, and that this result was secured about two weeks after the treatment was commenced; that many of the active tubercles have entirely disappeaied, and that all are disappearing. That the ulcerating nodule, the size of a crown, upon which a scab existed when the treatment was started, has now healed under the scab and flattened out; that the nodule next to it has likewise assumed a like shape, and is far less prominent; that the skin in which the disease had returned is now mavable, whereas, before the treatment, it was quite fixed; and', lastly, that the tubercle, which was situated at the end of the scar in the axilla appears to be undergoing a withering process. Indeed, from these facts no other conclusions can be drawn than that, as a result of the treatment, the disease has been scotched, if not killed; that the acute form of the disease which existed on its recurrence has been entirely checked and exchanged for an atrophying condition, which it seems reasonable to believe may pass on by the continuation of the treatment, to the removal of the local manifestation of disease. It is likewise to be emphasised that the treatment itself is absolutely painless, and that it relieves pain if present after the application of the rays for a few days. In a second case of recurrent cancer, now in the hospital, similar changes are also to be observed to those just recorded. With such facts before us, as have thus been briefly described, it seems reasonable to suggest that the treatment of local cutaneous forms of cancer, by the means we are now considering, is most hopeful and that such treatment should be applied in all cases when the disease is not otherwise suitable for the operative treatment. That in all recurrent cases of carcinoma, as illustrated by the example you have just seen, the treatment should certainly be employed. What it may do in cases of sarcoma has yet to be tested; for my own part, I should anticipate good success, for there seems to be but little doubt that the $x$ rays have a destructive influence upon cell life, the extent of which has yet to be worked out, but which is full of promise. Let me, however, again repeat that we must not yet talk of cancer cures, although we seem to be quite justified in saying that these $x$ rays will kill pain and retard growth. How much more they may do has still to be worked out; but what we have done at our local hospital, in which all of you take so much interest, has been so hopeful, that I have thought it only right to present to you these brief notes; and I do so with the hope that you may help us in our work, and in so doing help those who fall into your hands for treatment.

The President and several members of the Society took part in the discussion which followed. PAPER.

Mr. Yearsley read a paper entitled The Diagnosis and Treatment of Pain in the Ear.

\section{The Clinical Society : A CorRection.}

Mr. Cuthbert S. Wallace (Upper Wimpole Street) writes : In the discussion at the Clinical Society on intracranial section of the fifth nerve you report me as saying that the "temporal route" had fallen into disrepute in America. As a matter of fact, I quoted an American author into disuse. 